\title{
Aderência in vitro do Staphylococcus epidermidis e da Pseudomonas alcalig'enes em lentes intra-oculares
}

\author{
In vitro adherence of Staphylococcus epidermidis and Pseudomonas \\ alcaligenes to intraocularlenses
}

\author{
Patrícia Ioschpe Gus ${ }^{1}$ \\ Jacobo Melamed ${ }^{2}$ \\ Afonso Barth ${ }^{3}$ \\ Berno Dieter Sudhaus ${ }^{4}$ \\ Guilherme Quinto $^{5}$ \\ Guilherme Herrmann Matos ${ }^{6}$ \\ Marcia Cristina Bayer ${ }^{7}$
}

\section{RESUMO}

Objetivo: Quantificar e comparar a aderência in vitro das bactérias Staphylococcus epidermidis e Pseudomonas alcaligenes em diferentes tipos de lentes intra-oculares (LIOs). Métodos: Quatorze lentes intraoculares foram usadas no experimento. Quatro de polimetilmetacrilato (PMMA), quatro de silicone, quatro de hidrogel e duas de acrílico. Oito lentes intra-oculares foram colocadas em oito tubos de ensaio contendo $4 \mathrm{ml}$ de suspensão de Pseudomonas alcaligenes, e seis lentes intraoculares foram colocadas em seis tubos de ensaio contendo $4 \mathrm{ml}$ de suspensão de Staphylococcus epidermidis. A concentração do caldo utilizada para o teste de aderência foi de $10^{8}$ unidades formadoras de colônias por mililitro $(\mathrm{CFU} / \mathrm{mL})$ que corresponde a 0,5 na escala de McFarland. As lentes foram incubadas a $37^{\circ}$ por duas horas. Após, foram removidas dos caldos e enxaguadas em água destilada estéril por duas vezes. As lentes foram cultivadas em placas de ágar-sangue a $35-37^{\circ} \mathrm{e}$ evaliadas a cada $24 \mathrm{~h}$ por um período de $72 \mathrm{~h}$. Nas amostras que tiveram crescimento bacteriano, foram contadas as colônias utilizando os métodos convencionais de laboratório. Todos os ensaios foram executados em duplicata. Resultados: A aderência do Staphylococcus epidermidis nas lentes de PMMA foi menor se comparada com as de silicone e de hidrogel. A aderência da Pseudomonas alcaligenes nas lentes de hidrogel foi menor se comparada com as de silicone, PMMA e acrílico. Conclusão: Os resultados sugerem que a aderência do Staphylococcus epidermidis e da Pseudomonas alcaligenes nas lentes intra-oculares é influenciada pelo tipo de material da lente e pela espécie do microorganismo. A aderência bacteriana pode ter papel importante na patogenicidade da endoftalmite pós-cirurgia de catarata.

Descritores: Extração de catarata/efeitos adversos; Aderência bacteriana; Contagem de colônia microbiana; Endoftalmite/etiologia; Staphylococcus epidermidis/isolamento e purificação; Pseudomonas alcaligenes/isolamento \& purificação; Lentes intra-oculares/ microbiologia; Polimetil metacrilato; Elastômeros de silicone

\section{INTRODUÇÃO}

Endoftalmite é uma complicação rara e de mau prognóstico que ocorre em pós-cirurgia de catarata. Os trabalhos realizados nos Estados Unidos da América revelam uma incidência de endoftalmite que varia de 0,1 a 0,6\%. Apesar da incidência baixa e do tratamento precoce, o resultado final tende a deteriorar gravemente a visão ${ }^{(1-5)}$.

Embora nem sempre se consiga determinar com exatidão o patógeno envolvido, imagina-se que a flora bacteriana das pálpebras, conjuntiva e da 
drenagem lacrimal, seja a fonte do organismo infectante ${ }^{(2,6)}$. A contaminação da câmara anterior durante a cirurgia pode promover o caminho para a bactéria aderir-se a lente intra-ocular $\mathrm{LIO}^{(2,7-9)}$. Alguns autores relatam que uma pequena incisão cirúrgica pode diminuir o risco de contaminação da câmara anterior $^{(7-8)}$. Outros fatores de risco são soluções e instrumentos utilizados na cirurgia e a flora do próprio cirurgião ${ }^{(6)}$.

A análise da flora conjuntival e do humor aquoso póscirurgia de catarata sugerem que a maioria dos patógenos causadores de endoftalmite são introduzidos no olho durante o procedimento cirúrgico. Este fato provavelmente ocorre através do contato da LIO com os tecidos oculares externos antes dela ser implantada ${ }^{(1-13)}$.

O presente trabalho deseja quantificar e comparar a aderência in vitro das bactérias Staphylococcus epidermidis e a Pseudomonas alcaligenes em diferentes tipos de LIOs. O critério de escolha das bactérias baseou-se na primeira fase deste estudo, que identificou os microorganismos presentes na flora conjuntival de nove pacientes HIV positivos com catarata $^{(14)}$. Nesse estudo, a bactéria mais prevalente foi o Staphilococcus epidermidis $(33,33 \%)$, sendo seguida pela Pseudomonas alcaligenes (11,11\%), pelo Corynebacterum $s p$ $(11,11 \%)$ e pelo Acinetobacter sp $(5,56 \%)^{(14)}$.

\section{MÉTODOS}

\section{Microrganismos}

O Staphylococcus epidermidis e a Pseudomonas alcaligenes foram identificados e isolados na primeira fase deste estudo $^{(14)}$.

\section{Lentes intra-oculares}

Foram utilizados 14 lentes intra-oculares, sendo quatro de polimetilmetacrilato - PMMA (Allergan PS43NB e PS26TB, Alcon MC50BD e LX10BD), quatro de silicone (duas Allergan SI40NB e duas Allergan SI30NB), quatro de hidrogel (Storz H60M) e duas de acrílica (Alcon MA30BA e MA60MB).

\section{Descrição da técnica in vitro}

\section{Fase de preparação do caldo}

As bactérias selecionadas foram degeladas e semeadas em outra cultura de ágar-sangue. Após revitalizadas, foram cultivadas em caldo glicosilado por um período de 24 horas. A concentração do caldo utilizada para o teste de aderência foi de $10^{8}$ unidades formadoras de colônias por mililitro ( $\mathrm{CFU} / \mathrm{mL})$, o que corresponde a 0,5 na escala de McFarland. Foram preparados 14 caldos contendo $4 \mathrm{ml}$ cada, oito com Pseudomonas alcaligenes e seis com Staphylococcus epidermidis.

\section{Fase de aderência}

Após detectado o crescimento bacteriano no caldo, as lentes foram nele colocadas com o auxílio de um porta-LIO esterelizado e lá permaneceram por duas horas a $37^{\circ} \mathrm{C}$. Em cada caldo contendo Pseudomonas alcaligenes foi colocada uma lente intra-ocular. Totalizou-se: duas de acrílico, duas de silicone, duas de PMMA e duas de hidrogel, uma lente em cada caldo. Nos seis caldos que continham Staphylococcus epidermidis foram colocadas duas lentes de silicone, duas de PMMA e duas de hidrogel, uma lente em cada caldo. Cultivamos as lentes de acrílico no caldo que continha Pseudomonas alcaligenes por duas razões: por se tratar de uma bactéria pouco comum na flora ocular e pelo fato de nunca ter sido submetida a estudo semelhante.

\section{Fase de lavagem e esgotamento}

Passado o período de duas horas, o caldo foi escoado em uma peneira esterilizada e enxaguada com $40 \mathrm{ml}$ de água destilada estéril. Após, a lente era retirada da peneira com o auxílio de um pinça estéril e mergulhada novamente em uma placa de Petri estéril contendo $20 \mathrm{ml}$ de água destilada estéril. Com o término do segundo enxágüe a lente era retirada da placa de Petri com o auxílio de uma alça de platina estéril e transportada para a placa de ágar-sangue. Utilizando uma alça de acrílico estéril foi realizado o esgotamento de um dos lados da lente na metade do meio de cultura. Depois, a lente era virada com a alça de acrílico e feito o esgotamento na metade restante do meio de cultura. $\mathrm{O}$ primeiro lado da lente que tocou o meio de cultura foi considerado como lado A, e a outra metade como lado B. Ao término do esgotamento as placas eram incubadas a $37^{\circ}$ por $72 \mathrm{~h}$.

\section{Contagem das colônias}

As colônias foram contadas a cada $24 \mathrm{~h}$ por um período de $72 \mathrm{~h}$. As colônias que cresceram na placa de ágar-sangue ao final deste período representam as bactérias previamente aderidas às LIOs. Conforme a padronização do serviço de bioquímica do Hospital de Clínicas de Porto Alegre, o número de colônias foi contado até 1000 , acima deste valor foi classificado como mais de 1000 colônias. Este estudo não avaliou o comportamento da aderência bacteriana em relação ao tamanho ou área de cada LIO.

\section{RESULTADOS}

A tabela 1 mostra o crescimento da Pseudomonas alcaligenes nos quatro grupos de LIOs. A densidade da aderência é expressa pelo número de colônias formadas nas placas de ágar-sangue após 72h. As lentes de hidrogel tiveram o menor grau de aderência bacteriana se comparadas com as LIOs de acrílico, de silicone e de PMMA (Gráfico 1). A densidade de bactérias aderidas nas lentes de silicone e de PMMA foram semelhantes e menores que as de acrílico. O grau de aderência da Pseudomonas alcaligenes em ordem decrescente foi: acrílico, PMMA, silicone e hidrogel.

A tabela 2 mostra a aderência do Staphylococcus epidermidis em três grupos de LIOs. Não houve diferença expressiva entre as lentes de PMMA, silicone e hidrogel (Gráfico 2). 

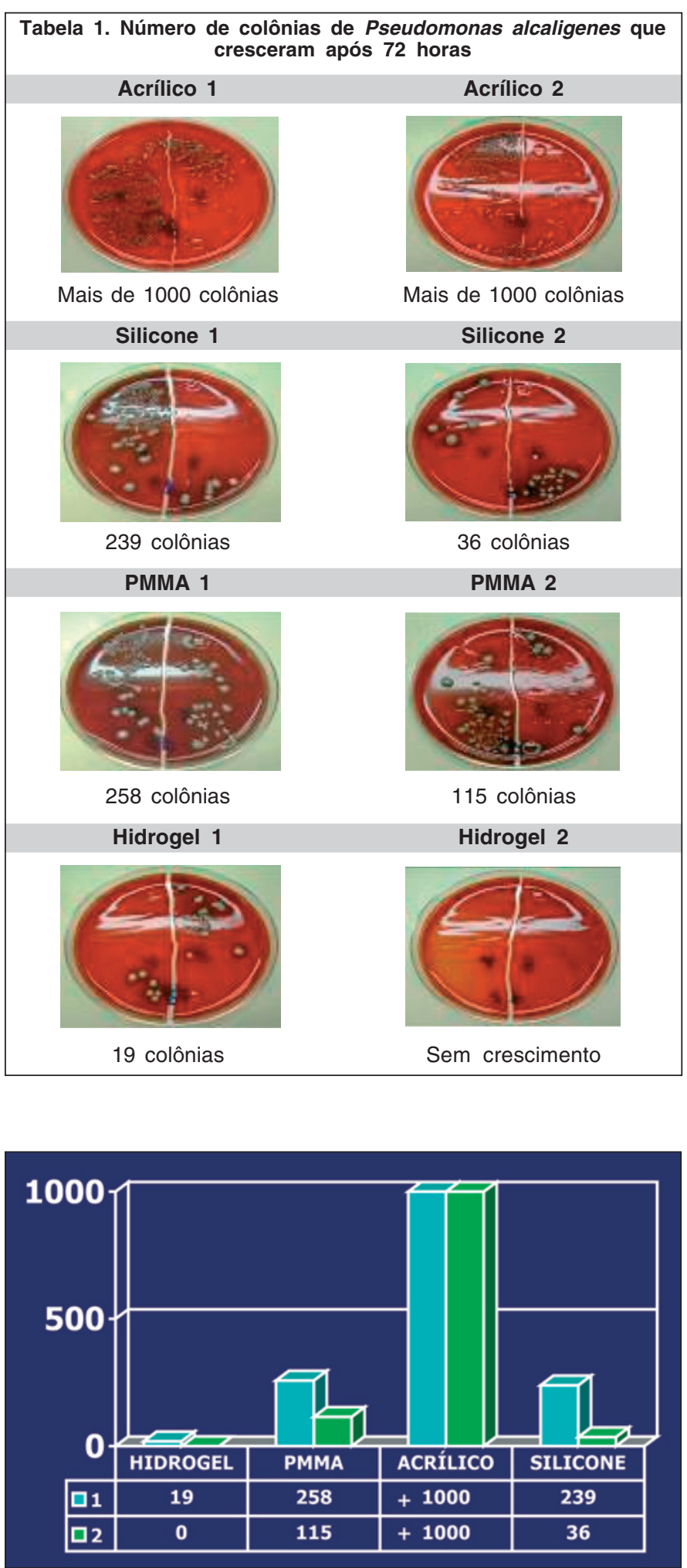

Gráfico 1 - Comparação das duplicatas cultivadas em Pseudomonas alcaligenes

Entretanto, a segunda lente de PMMA testada teve aderência bacteriana menor se compararmos com as lentes de silicone, hidrogel e com a primeira lente de PMMA testada.
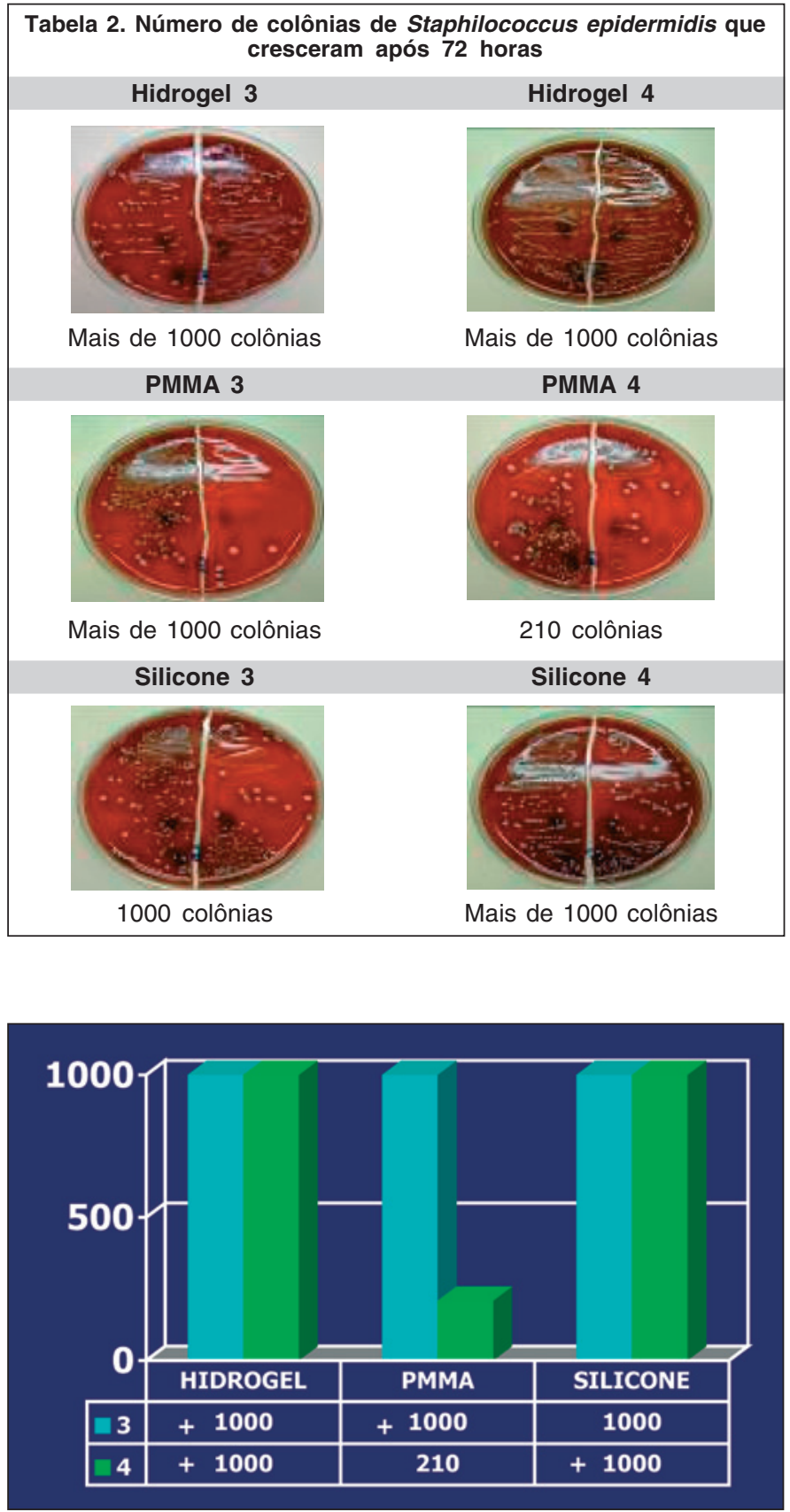

Gráfico 2 - Comparação das duplicatas cultivadas em Staphilococcus epidermidis

\section{DISCUSSÃO}

O objetivo deste estudo in vitro foi investigar a aderência bacteriana em diferentes tipos de LIOs usadas rotineiramente em cirurgia de catarata. Partimos da idéia de que a contaminação das LIOs ocorre, na maioria das vezes, através do contato da lente com os tecidos extraoculares durante o processo de sua implantação ${ }^{(1-13)}$. Esse aumento de bactéria aderida na LIO pode evoluir para endoftalmite, especialmente em pacientes imunodeprimidos, como é o caso dos portadores de HIV- 
$\operatorname{positivos}^{(1,6,15-16)}$. A aderência bacteriana na superfície das LIOs ocorre em duas fases: absorção e aderência. A absorção é mediada por forças físicas e depende das características do microorganismo e do material da lente. Na fase de aderência a bactéria produz uma cápsula de polissacarídeo sobre a superfície da LIO, que os protege da opsonização, da fagocitose, da ação do complemento e dos macrófagos ${ }^{(9-10)}$.

Em estudo retrospectivo realizado no Reino Unido em 2003, alguns autores avaliaram a incidência de endoftalmite pós-cirurgia de catarata ${ }^{(17)}$. Nesse trabalho foram comparadas três técnicas cirúrgicas: extração extracapsular, facoemulsificação com lentes dobráveis e rígidas e facoemulsificação com lentes injetáveis. As lentes injetáveis foram associadas com um menor risco de endoftalmite pós-operatória, apresentando uma incidência de $0,028 \%$ (três pacientes) em 10.815 casos. Os autores acreditam que essa baixa incidência ocorre pelo fato da lente injetável não fazer contato com a superfície ocular ${ }^{(17)}$.

Muitos autores têm estudado a aderência de diferentes bactérias aos diferentes materiais de $\mathrm{LIO}^{(3-5,7-8,10-12,18)}$. As bactérias mais estudadas são Staphylococcus epidermidis, Staphylococcus aureus e a Pseudomonas aeruginosa. Embora os resultados não sejam sempre concordantes, a maioria dos estudos demonstram que o material mais aderente é o acrílico e o menos aderente é o PMMA ${ }^{(3-5,10-12)}$. O comportamento bacteriano é potencialmente variável de acordo com os diferentes sorotipos das bactérias, diversas condições de imunidade dos pacientes e diferenças ambientais ${ }^{(2-5,7-12)}$.

A Pseudomonas alcaligenes é uma bactéria do tipo bacilo gram-negativo. Sua capacidade de atuar como patógeno humano é demonstrada em raras ocasiões. Existem relatos do seu envolvimento em infecções oculares, empiemas e até em casos de endocardite ${ }^{(25)}$. Apesar de raros os relatos, não podemos afirmar que este agente não seja comum na flora conjuntival de pacientes imunodeficientes ${ }^{(19-24)}$. Comparada com outros tipos de Pseudomonas, apresenta o mesmo comportamento em meios de cultura, ou seja, são bioquimicamente semelhantes $^{(26)}$. Outras espécies de Pseudomonas, exceto a Pseudomonas aeruginosa, raramente causam infecção. Devido à baixa virulência, as infecções causadas por estas espécies são frequentemente iatrogênicas ou estão associados com a administração de soluções contaminadas ${ }^{(25)}$. A transmissão deste patógeno é desconhecida ${ }^{(25-26)}$.

$\mathrm{O}$ estudo evidenciou que a Pseudomonas alcaligenes foi menos aderente em lentes de hidrogel quando comparada com os outros tipos de LIOs testadas. Na literatura não há trabalhos que relacionem a aderência da Pseudomonas alcaligenes ou outra espécie de Pseudomonas em lentes de hidrogel. As lentes de silicone e de PMMA tiveram resultados semelhantes, mostrando maior aderência à Pseudomonas alcaligenes que a lente de hidrogel e menor que a de acrílico. Apesar de não haver trabalhos que utilizaram esta bactéria, achamos interessante relatar um estudo que utilizou a Pseudomonas aeruginos $^{(4)}$. Neste trabalho, com o uso microscopia eletrônica, foi quantificado e comparado a aderência in vitro da Pseu- domonas aeruginosa em três tipos de LIOs: PMMA, silicone e acrílico. Os resultados encontrados em ordem crescente de aderência foram: acrílico, PMMA e silicone ${ }^{(4)}$.

O Staphylococcus epidermidis é uma bactéria do tipo coco Gram-positivo responsável por $60 \%$ dos casos agudos de endoftalmite ${ }^{(2)}$. Este organismo é normalmente considerado de baixa patogenicidade, entretanto há cada vez mais evidências indicando a sua responsabilidade em muitas infecções oculares. Além disso, a sua suscetibilidade ao antibiótico é imprevisível pela existência de Staphylococcus epidermidis multiresistentes $^{(7)}$.

Nossos resultados mostraram que a lente de PMMA teve menor aderência de Staphylococcus epidermidis do que as lentes de silicone e de hidrogel. Alguns autores, também evidenciaram que as lentes de PMMA foram menos permissivas ao Staphylococcus epidermidis. A aderência avaliada pela microscopia eletrônica foi encontrada principalmente nas áreas de superfície irregular ${ }^{(7,10)}$. Em outro estudo, também utilizando a microscopia eletrônica, foi comparada a aderência bacteriana nas lentes de silicone, PMMA e hidrogel ${ }^{(18)}$. O estudo relatou menor aderência nas lentes de hidrogel quando comparadas com as de silicone e maior que as de $\mathrm{PMMA}^{(18)}$.

Acreditamos que o crescimento bacteriano nas placas de ágar-sangue é a representação das bactérias previamente aderidas nas LIOs. Isto é comprovado, pois, no momento que retiramos as lentes do caldo e enxaguamos duas vezes, estamos removendo o excesso do caldo e as bactérias fracamente aderidas a elas. As bactérias fortemente aderidas permaneceram na lente e foram transferidas para a placa de ágar-sangue com o processo de esgotamento. $\mathrm{O}$ estudo apresentou resultado divergente apenas entre as lentes de PMMA cultivadas com Staphylococcus epidermidis. Provavelmente isto ocorreu por uma falha durante a manipulação das lentes de PMMA ou por contaminação das placas de ágar-sangue por outra espécie de bactéria. Apesar disto, o fato das demais lentes de igual material terem tido resultados compatíveis sugere que a metodologia utilizada deve ser adequada.

\section{CONCLUSÃO}

A identificação dos fatores que promovem a aderência bacteriana na superfície das LIOs é de extrema importância para determinar como esses organismos causam endoftalmite. O nosso estudo sugere que a aderência bacteriana em LIOs é influenciado pelo tipo de material da lente e pela espécie do microorganismo. Estudos como este podem ser úteis no antibioticoprofilaxia da endoftalmite para pacientes com características semelhantes ao grupo estudado.

\section{AGRADECIMENTOS}

Aos fornecedores dos laboratórios, incluindo a Sulentes do Rio Grande do Sul. 


\section{ABSTRACT}

Purpose: To quantify and compare the in vitro adherence of Staphylococcus epidermidis and Pseudomonas alcaligenes to different intraocular lenses (IOLs). Methods: Fourteen intraocular lenses were used in the experiment. Four of polymethylmethacrylate (PMMA), four of silicone, four of hidrogel and two of acrylic. Eight intraocular lenses were placed in eight test tubes containing $4 \mathrm{ml}$ of Pseudomonas alcaligenes suspension, and six intraocular lenses were placed in six test tubes containing $4 \mathrm{ml}$ of Staphylococcus epidermidis suspension. The bacterial suspension used for adherence tests was $10^{8}$ colony-forming units per milliliter $(\mathrm{CFU} / \mathrm{mL})$ which corresponds to 0.5 in the scale of McFarland. The lenses were incubated at $37^{\circ}$ for two hours. After this, intraocular lenses were removed from the test tubes and dried twice with the use of distilled and sterile water. The material was spread on blood-agar for cultivation at $35-37^{\circ} \mathrm{C}$ and was evaluated every 24 hours up to 72 hours. In the samples where there was bacterial growth, the colonies were counted using the conventional laboratory methods. All assays were performed in duplicate. Results: Adherence of Staphylococcus epidermidis to PMMA intraocular lenses was lower than to hydrogel and silicone intraocular lenses. Adherence of Pseudomonas alcaligenes to hydrogel intraocular lenses was lower than to PMMA, acrylic and silicone intraocular lenses. Conclusions: Results suggest that in vitro adherence of Staphylococcus epidermidis and Pseudomonas alcaligenes to intraocular lenses is influenced by type of material of the lens and by microorganism species. Bacterial adherence may play a role in the pathogenesis of some forms of endophthalmitis after cataract surgery. More in vitro and clinical studies are necessary to elucidate the mechanisms by which Staphylococcus epidermidis and Pseudomonas alcaligenes cause endophthalmitis.

Keywords: Cataract extraction/adverse effects; Bacterial adhesion; Colony count, microbial; Endophthalmitis/etiology; Staphylococcus epidermidis/isolation \& purification; Pseudomonas alcaligenes/isolation \& purification; Eye infections, bacterial/microbiology; Lenses, intraocular/microbiology; Polymethylmethacrylate; Silicone elastomers

\section{REFERÊNCIAS}

1. Kresloff MS, Castellarin AA, Zarbin MA. Endophthalmitis. Surv Ophthalmol. 1998;43(3):193-224.

2. García-Saenz MC, Arias-Puente A, Fresnadillo-Martinez MJ, Matilla-Rodrigues A. In vitro adhesion os staphylococcus epidermidis to intraocular lenses. J Cataract Refract Surg. 2000;26(11):1673-9.

3. Schauersberger J, Amon M, Aichinger D, Georgopoulos A. Bacterial adhesion to rigid and foldable posterior chamber intraocular lenses. J Cataract Refract Surg. 2003;29(2):361-6.

4. Gabriel MM, Ahearn DG, Chan KY, Patel AS. In vitro adherence os pseudomonas aeruginosa to four intraocular lenses. J Cataract Refract Surg. 1998;24(1): 124-9.

5. Sanches Buenfil E, Garcia Garduño LM. Resultados de cultivos de vítreo e endoftalmitis secundária a cirurgia de catarata. Rev Mex Oftalmol. 1998;72(5): 229-32.

6. Kanski JJ. Oftalmologia clínica. 3a ed. Rio de Janeiro: Rio Med Livros; 2000.

7. Pinna A, Sechi LA, Zanetti S, Delogu D, Carta F. Adherence of ocular isolates of staphylococcus epidermidis to ACRYSOF intraocular lenses. A scanning electron microscopy and molecular biology study. Ophthalmology. 2000;107(12): 2162-66.

8. Ng EW, Barrett GD, Bowman R. In vitro bacterial adherence to hydrogel and poly (methyl methacrylate) intraocular lenses. J Cataract Refract Surg. 1996; 22(Suppl 2):1331-5.

9. Jalali S, Das T, Gupta S. Presumed noninfectious endophthalmitis after cataract surgery. J Cataract Refract Surg. 1996;22(10):1492-7.

10. Pinna A, Zanetti S, Sechi LA, Usai D, Falchi MP, Carta F. In vitro adherence of Staphylococcus epidermidis to polymethyl methacrylate and acrysof intraocular lenses. Ophthalmology. 2000;107(6):1042-6. Comment in: Ophthalmology. 2001;108(9):1518-9.

11. Schemann JF. Scanning electron microscopic study of anterior chamber intraocular lens: latent endophthalmitis. Ophthalmologica. 1987;195(1):7-12.

12. Christensen GD, Baddour LM, Simpson WA. Phenotypic variation of staphylococcus epidermidis slime production in vitro and in vivo. Infect Immun. 1987;55(12):2870-7.

13. Raskin ME, Speaker MG, McCormick SA, Wong D, Menikoff JA, PeltonHenrion K. Influence of haptic materials on the adherence of staphylococcus to intraocular lenses. Arch Ophalmol. 1993;111(2):250-3.

14. Gus PI, Melamed J, Bayer MC, Quinto G, Matos GH, Sudhaus BD, et al. Flora conjuntival aeróbia de HIV positivos. Rev Bras Oftalmol. 2004;63(3):170-5.

15. Gritz DC, Scott TJ, Sedo SF, Cevallos AV, Margolis TP, Whitcher JP. Ocular flora of patients with AIDS compared with those of HIV-negative patients. Cornea. 1997;16(4):400-5.

16. Miyamoto C, Yashiro S, Nagata Y, Nagataki S. [Ocular complications in patients infected with human immunodeficiency virus seen at the Acquired Immunodeficiency Syndrome Clinical Center]. Nippon Ganka Gakkai Zasshi. 2001;105(7):483-7. Japanese.

17. Mayer E, Cadman D, Ewings P, Twomey JM, Gray RH, Claridge KG, et al. A 10 year retrospective survey of cataract surgery and endophthalmitis in a single eye unit: injectable lenses lower the incidence of endophalmitis. $\mathrm{Br} \mathrm{J}$ Ophthalmol. 2003;87(7):867-9

18. Cusumano A, Busin M, Spitznas M. Is chronic intraocular inflammation after lens implantation of bacterial origin? Ophthalmology. 1991;98(11):1703-10.

19. Khorozo D, Thompson R. The bacterial flora of the normal conjunctiva. Am J Ophthalmol. 1935;18:1114.

20. Tamayo Lamothe E, Jaime Suárez G, López Paredes S. Flora conjuntival normal: studio realizado en el preoperatorio de 100 pacientes. Rev Cuba Oftalmol. 1990;3(2):137-47.

21. Figueroa P, Emparanza JL, Thompson L, Silva M, Verdaguer J. Estudio de la flora conjuntival y palpebral en poblacion intrahospitalaria. Arch Chil Oftalmol. 1983;40(1):47-8

22. Campos MSQ, Sato EH, Nosé W, Mós EN, Santos MAA. Microbiota anaeróbica do saco conjuntival humano normal. Arq Bras Oftalmol. 1989;52(6):193-5.

23. Gritz DC, Scott TJ, Sedo SF, Cevallos AV, Margois TP, Whitcher JP. Ocular flora of patients with AIDS compared those of HIV-negative patients. Cornea. 1997;16(4):400-5.

24. Friedlaender MH, Masi RJ, Osumoto M, Smolin G, Ammann AJ. Ocular microbial flora in immunodeficient patients. Arch Ophthalmol. 1980;98(7): 1211-3.

25. Forbes BA, Sahm DF, Weissfeld AS. Bailey \& Scott's diagnostic microbiology. 10th ed. Saint Louis: Mosby; 1998.

26. Murray PR, Baron EJ, Pfaller MA, Tenover FC, Yolken RH. Manual of Clinical Microbiology. 7a ed. Washington (DC): American Society for Microbiology; 1999. 